\title{
Malaysian ESL Students' Syntactic Accuracy in the Usage of English Modal Verbs in Argumentative Writing
}

\author{
Jayakaran Mukundan ${ }^{1}$, Khairil Anuar bin Saadullah ${ }^{1}$, Razalina binti Ismail ${ }^{1} \&$ Nur Hairunnisa binti Jusoh \\ Zasenawi $^{1}$ \\ ${ }^{1}$ Department of Educational Studies, Universiti Putra Malaysia, Selangor, Malaysia \\ Correspondence: Jayakaran Mukundan, Department of Educational Studies, Universiti Putra Malaysia, 43400 \\ UPM Serdang, Selangor, Malaysia. E-mail: jayakaranmukundan@yahoo.com
}

$\begin{aligned} & \text { Received: May 13, } 2013 \quad \text { Accepted: October 10, } 2013 \quad \text { Online Published: November 5, } 2013 \\ & \text { doi:10.5539/elt.v6n12p98 }\end{aligned}$ URL: http://dx.doi.org/10.5539/elt.v6n12p98

\begin{abstract}
This research studied the use of modals in argumentative written tasks by Form 5 Malaysian secondary school ESL students. The aim of this study was to examine the use of English modals at the syntactic level from data presented in the MCSAW Corpus. The research design comprised a qualitative technique through discourse analysis aided by descriptive statistics from a concordance, which was utilized to identify the modal verbs used by the Form 5 level in Malaysian schools. The research findings showed that Malaysian students had little problem using modal verbs grammatically in argumentative writing. It was also found that Malaysian students preferred to use a lot of modals in their writings. However, the use of these modals was limited to a few words only. It was concluded that despite the inaccuracies in terms of meanings, most students were able to use syntactically accurate modals in their sentences. Several recommendations are proposed with the aim of improving the teaching of modal verbs in Malaysian schools.
\end{abstract}

Keywords: modals, corpus, syntactic accuracy

\section{Introduction}

One of the main problems in learning and teaching English as a second language is the complexity of the modal auxiliary system. Different notions are expressed in the standard formal English which may range from permissions to obligations. Modals, in some ways, play a role to the semantics of useful communications as it forms an essential aspect of the society and being the most important element in human language. The knowledge of grammar is considered important to facilitate communication and without it communication will fail due to lack of structure. According to Thompson (2002), modals are considered a complex unit and one may not find it easy to put together such intricacy into something that is meaningful to learners. If one managed to reduce the complexity of the modals, ESL learners may find learning English modals to be less problematic.

In language learning, Ferris (2002) stated that verb forms relating to modals are considered problematic to both first (L1) and second language (L2) speakers. L1 speakers tend to make grammatical mistakes when faced with this problem. For example, where L1 speakers make errors, L2 speakers are even more compelled and capable of making the same errors and even more in areas of formation of the verb phrases, passive and conditional forms, misuse of modals, gerunds, infinitives and other grammatical items. The need to identify the errors in written discourse, as well as to have a certain amount of knowledge on correcting those errors before dispatching the knowledge to students, is important to educators (Ferris, 2002).

It should be noted that Malaysian teachers of ESL, most of them L2 speakers themselves, are not sure how much detail should be used while explaining grammatical items to their students (Hawanum, 2004). Many problems surfaced in the teaching of grammar when the Malaysian New English Language Curriculum, based on a communicative model of language teaching learning, was implemented (Pillay and North, 1997). Vethamani (2001) added that having students of mixed abilities and mixed interests in a classroom may have made the problem more difficult for language teachers. Teachers were not certain how grammar should be fitted into the lesson plan due to lack of clarity among them regarding the role of grammar in the new curriculum.

According to Hughes and Heah (1993), identifying the correct use of modals is the main problem faced by ESL learners in Malaysia. As shown in the error analysis of Form Four compositions by Rosli and Malachi (1989), 
both urban and rural students faced difficulties when dealing with modal auxiliary since it is formed with a verb phrase. Wong (1983) stated that the modal auxiliary system of the English language is very complex as the same modals are used to express different notions of possibility, certainty and probability along with the concepts of ability, obligation, permission and inclination. To avoid such confusion among learners, teachers need to be very careful when teaching this part of grammatical item.

The teaching of English language has always been a main concern in multiracial Malaysia and is often vastly highlighted in the media. Several steps have been proposed in the teaching of the grammar of the second and foreign language, especially in the teaching of modals. Byrd (2004) discusses the teaching and learning of modals from the easy items to the more difficult ones. However, she discusses and foresees that there is a problem in determining what is difficult and also easy and to whom it is difficult or easy which also needs to be given due consideration.

The modals "can", "could", "will", "should", "may", "might", "must", "need to" and "have to" listed by the Curriculum Development Center (CDC) of the Ministry of Education Malaysia (MoE) for the Integrated Secondary School Curriculum, are used to cover a broad semantic area. These modal verbs are used extensively across the notional categories in the system (de Silva, 1981). Malaysian ESL students also have the tendency to use these modals in many different ways and meanings, which could possibly lead to incoherence and misunderstanding. Thus, with these few basic modals listed in the syllabus, this study seeks to investigate the use of modals by ESL learners in Malaysia.

The main purpose of this study is to investigate and determine the usage of English modal verbs at the syntactic level from data made available by the Malaysian Corpus of Students' Argumentative Writing (MCSAW). The focus of this study has also been narrowed down to examining the use of modal verbs in written tasks of form 4 , form 5 and college ESL learners.

\subsection{Research Questions}

1) To what extent is Malaysian ESL learners' use of English Modals syntactically accurate?

2) Which modal verbs are frequently used by Malaysian students?

\section{Literature Review}

\subsection{Corpus Studies in Malaysia}

Many corpus based studies have been carried out throughout the decade in Malaysia. Such corpus-based analysis studies include investigation on Malaysian textbooks which focus on the distribution and colligation patterns of articles, phrasal verbs, accuracy of modal auxiliary verbs and description on the lexical collocations (Mukundan and Menon, 2008, Zarifi and Mukundan, 2012). From the studies, it was found that textbooks failed to fulfill the conditions on verb teaching set by the Malaysian Form 2 English Language syllabus and that the verbs taught by the textbooks made the verb acquisition difficult for the learners (Mukundan and Aziz, 2009, Mukundan,, Leong and Nimehchisalem, 2012). According to Mukundan and Khojasteh (2011), corpus-based study tend to provide a sense of familiarity with the prescribed textbooks' content, therefore helping educators to identify the strengths and weaknesses in textbooks already in use as well as to overcome the inconsistency in order to achieve a higher degree of authenticity in textbook corpus.

\subsection{Modals and Modality}

Modality, which is expressed by modals, is one of the more complex natures of English grammar that any ESL learner should understand. Second language learners, according to Quirk and Stein (1990), find it very difficult to learn the grammar of English language, which as Greenbaum (1991) describes is a set of rules to combine words in the language into larger units. Leech, Deuchar and Hoogenraad (1982), however, perceive grammar as a mechanism that serve as a set of rules in putting words together in order for us to communicate. Therefore, to send our messages across and to communicate with other people, we need to acquire grammar rules (i.e. the modal verbs) in order for us to communicate.

According to Hoye (1997), the study of modality in the English language is the most persistent and fascinating areas of philosophical and linguistic inquiry.He added that modals are not used to express statements of facts; but rather general statements that represent the notion of the mind or events that may or may not take place in the future. This, plus the fact that most modal verbs have similar core meanings, is the reason why the modal auxiliary system is considered as the most difficult aspect of the English language for linguists and language learners (Reppen et al., 2002). Thompson (2002) added that, due to the meanings depicted by each modal verb, learners may find learning modals to be confusing. Therefore, ESL teachers should equip themselves with ample 
knowledge on the concept of modality to prevent confusion and misunderstanding that might occur during the learning process.

\subsection{Modals and Pedagogical Aspects}

Previous studies on modal auxiliary verbs have focused on how they influence the meaning of phrases or sentences with modals. According to Thompson (2002), modal auxiliary verbs provide a variety of meanings depending on how they are used. In their studies, Coates (1983) and Palmer (1990) have listed modality as semantic concepts where each modal may have a list of meanings. Plus, Leech (1971) and Quirk et al. (1985), through their research, concurred in studying modal verbs by listing and giving each modal the meaning that it may cover.

Palmer (1990) states that the meanings of modal verbs in English signify modality; and epistemic and deontic are two most semantically basic kinds of modality which differ from one another. According to him, modality is a semantic term and illustrates it as a grammatical category (Palmer, 1986).On the other hand, Hoye (1997) classifies modals as a mean used to express opinions, perceptions or intentions which are also congruous with the traditional concept of modality that describes the act of signifying probability, possibility, necessity as well as other related ideas of obligation, possibility and volition. Meanwhile, Lyon (1977) states that modality is a grammatical structure of the language that is neither true nor false, but rather deals with possibility or probability, or necessity or contingency. He also states that there is no general agreement on how to define mood and modality. The vagueness concerning semantic functions of modal verbs and lack of clear purpose in the formal system may result in having unclear guidelines concerning the limits of defining modals (Khojasteh, 2001). However, in grammar, modality often relates to modal auxiliary verb.

According to the systematic approach, modal auxiliary verbs are not the only modality characteristics and that there are many other features. Coates (1983) examines the semantic characteristics of modal auxiliaries as having the following characteristics:

1) Direct negation (can't, mustn't),

2) Inversion without do (can she, must she),

3) Code (Ali can wait and so can Joe),

4) Emphasis (Lisa could answer the questions),

5) No -s form for third person singular (*cans, *mights),

6) No non-finite forms (*to will, *shoulding),

7) No co-occurrence $(*$ might will).

The first four characteristics portray modal auxiliaries, while the next three portray the main verbs. It can be seen that, there is no apparent difference that could explain modals. By referring to Zadeh's (1965) "fuzzy sets theory", Coates classifies the class in which the transition from membership to non-membership happens gradually rather than abruptly.

\subsection{Modals and the English Language}

Hemeren (1978) states that the comprehensive content of modality in linguistic is only expected for the number of its expression in language to be equally comprehensive. Therefore, the list of the most frequent lexical ways of conveying modality according to Hemeren (1978) is as follows:

1) Nouns such as intention and determination; as well aschance, hope, presumption and expectation.

2) Adjectives such as obvious, likely conceivable, and possible; appropriate and necessary. Also in other adjectives like, surprise, able, sure and willing and finally certain and doubtful.

3) Adverbs like hardly and perhaps; evidently, fortunately, assuredly, regrettably, strangely and surprisingly.

4) Verbs: Main verbs such as doubt, believe, think and predict; suggest; prefer, want, desire, forbid and permit. Modal verbs like can, could, may, might, will, would, shall, should, must and ought to, which are familiar to the students.

Some modal verbs can be found mixed in a single sentence and may not take place separately. For example, in the sentence "Perhaps he might have built it" (Hemeren, 1978), the word perhaps and might are supporting each other. Another example is, "Certainly, he might have built it", where the modals appear in a sentence with no corresponding meaning, which Lyons (1977) describes as modally harmonic and non-harmonic. As mentioned by previous researchers, Celcie-Murcie and Larsen Freeman (1983), Thompson (2002), the workings of the 
diverse meanings of modals make them complicated for learners of ESL and are considered as one of the trickiest areas in English grammar teaching and learning.

\section{Method}

The use of discourse analysis applied to the research questions posted in this study helped researchers to answer the questions. The research was aimed to investigate how Malaysian ESL learners applied the use of modals in the written compositions using data obtained from the MCSAW Corpus. Three different levels: Form 4, Form 5 and College students in the Malaysian school system formed the data in the MCSAW Corpus which consisted of the students' written data. The title for the argumentative essay was 'Do you think Facebook has more advantages than disadvantages'. For the purpose of this study, only data from Form 5 students was used.

The application of Corpus-based approaches allows researchers to analyse and identify complex association patterns: the systematic ways where linguistic features are used together with other linguistic and non-linguistic features (Biber et al., 1998). Such known approaches are also applicable to educational linguistics, which can come in handy in planning successful materials and activities for classroom and workplace training, therefore students are able to familiarize with the language that is used in varied target settings and locations.

Being mainly a corpus-based study with data from the MCSAW Corpus, the study generally comprises of qualitative and quantitative methods. According to de Monnick (2005), the qualitative analysis targets a detailed explanation of the phenomenon under study while the quantification techniques give an accurate picture of absolute and relative (in) frequency of occurrence related to the particular phenomenon. Utilizing the concordance programme, assisted in generating a statistical report that helped in understanding and the analysis. Descriptive statistics helped the researchers to summarize the most important points of the data observed. On the other hand, the data abstracted can be used in inferential statistics which answers questions or is formulated as hypothesis (Oakes, 1998).

\subsection{The MCSAW Corpus}

The data used in this study was obtained from the MCSAW (Malaysian Corpus of Students' Argumentative Writing) Corpus. The first version of MCSAW was collected by TESL students who attended Professional Development Course in Master level at University Putra Malaysia in 2013 (Mukundan and RezvaniKhalajahi, 2013). The corpus consists of 406,500 running words (tokens) which have been chosen in order to identify the use of English modals in terms of functions and the frequency occurrences of these modals. The compositions have been written by 1010 students, 404 males and 606 females from schools and colleges in Selangor, Negeri Sembilan, Melaka and Kelantan. The data in the MCSAW Corpus was chosen as it consisted of written work of Malaysian students and was thought to be appropriate for researchers in their investigation in determining the application of how ESL learners used modals in their written work. The main purpose of the MCSAW Corpus was to form a baseline data of the Malaysian students English language proficiency in written forms and also to study developmental patterns through the data gained.

\subsection{Sampling of the Sub-Corpus}

The compilation of sub-corpus for the purpose of this study and the selective written tasks for the sub-corpus was grounded on purposive sampling. For this study alone, the purpose was to discover, fully understand and gain awareness on how students coped in using modals in their written work.

The sample size of the sub-corpus was decided based on a table by Krejcie and Morgan (1970) adapted by Powell (1991). Hence, for this study 274 argumentative compositions entitled 'Do you think Facebook has more advantages than disadvantages' from form 5 students were selected and analyzed.

For the data analysis, three independent raters were appointed to support in analysing for the preliminary study and also for the actual study. However, only one independent rater was used in reconfirming, cross-checking and verifying the analysis. The independent raterwas also briefed on the categories being used to synchronize analysis, which then allowed the researchers to answer the research questions.

\subsection{Discourse Analysis}

To analyse sentences in the written tasks the method of discourse was used. For this purpose in this study, the use of modals in students' written work needed to be analysed. The students' written work was examined with the inter-rater, directing to a more sensitive and, stronger analysis that a discourse analysis will allow. Discourse analysis is used to analyse the data so that language characteristics that spread across clause limitations can be focused (Biber, et al., 1998).

The independent rater read the texts through discourse analysis as it was important to understand the modals and 
the functions they represented in the students writing. The discourse analysis employed in this study would also tend to show if there were repetitious use of modals by these students.

\section{Findings and Discussion}

\subsection{Syntactic Analysis of Students'Usage of Modals}

Syntax is defined as a set of rules of how sentences, which consists of words, phrases and clauses, are formed, and human languages possess a remarkable variety of assembling the elements in sentences with rules that govern the arrangement (Biber et al., 2002; Carter and McCarthy, 2006). Various aspects need to be understood in order to study syntax: namely, how sentences are formed and how they are understood in particular languages and in a language generally (Stockwell, 1977). According to Van Valin (2001), a well-formed sentence is usually seen as grammatical and is in agreement to the rules and principles of the syntax of a particular language, while an ungrammatical sentence or ill-formed sentence violates one or more syntactic rules or principles.

In the study of syntax, the concept of structure is considered fundamental (Burton-Roberts, 1986). As the focus of this study was on the English modal system, the discussion in this section was focused on the grammatical accuracies and inaccuracies in the sentences constructed with modals by the students, specifically how ESL learners in Malaysia used modal verbs in their compositions. The usage of these words is categorized in terms of the five modal structures in order of preference, which follows the framework provided by Mindt (1995):

1) Modal + bare infinitive (e.g. "I will miss you.")

2) Modal + passive infinitive (e.g. "He will be punished.")

3) Modal + progressive infinitive (e.g. "You'll not be playing for the team anymore.")

4) Modal + perfect infinitive (e.g. "The annual revenue will have increased by then.")

5) Modal + perfect passive infinitive (e.g. "No harm will have been done.")

All sentences with modals were examined. A sentence with a modal which is followed by an inaccurate verb form is considered as syntactically inaccurate; for example, "We will receives feedback from friends about their reaction toward your feelings." (F5-746). This sentence is considered as inaccurate because of the verb form "receives" which syntactically should be "receive" following modal "will". Most of the occurrences of the modals in the study were followed by the infinitive construction: modal and a bare infinitive; thus it was easier to identify verb forms that were incorrect.

\subsection{Distribution of Syntactically Accurate and Inaccurate Modals}

Table 1 shows the frequency counts of syntactically accurate and inaccurate modals used in the argumentative essays.

Table 1. Distribution of syntactically accurate and inaccurate modals

\begin{tabular}{llll}
\hline Modals & Accurate & Inaccurate & Total no. of words \\
\hline Can/cannot/can't & 2051 & 131 & 2182 \\
Will/won't & 745 & 110 & 855 \\
Could/couldn't & 139 & 5 & 144 \\
May/may not & 126 & 10 & 136 \\
Should/shouldn't & 123 & 3 & 126 \\
Have/has/had to & 117 & 2 & 119 \\
Would/wouldn't & 116 & - & 116 \\
Must/mustn't & 93 & 12 & 105 \\
Might/might not & 92 & 4 & 96 \\
Shall/shan't & 1 & - & 1 \\
Total & 3584 & 277 & 3861 \\
\hline
\end{tabular}


Out of 3861 of the total modals identified, 3584 were syntactically accurate and only 277 were not, which made were only $7 \%$ of the population. The modal "can" was the most highly used by the students, with 2051 out of 2182 being syntactically accurate and 131 not. The second highest was the modal "will", where a total of 745 counts of the modal was found to be syntactically correct compared to 110 inaccurate usages of the word. The modals "could", "may", "should" and "have to" all scored marginally similar syntactically accurate numbers at $139,126,123$ and 117 respectively. The number of inaccurate modal verb phrases for each modal appears to be quite small compared to the accurate ones. This shows that: (1) Malaysian students have the knowledge to use these modal verbs, and (2) the students prefer to use the modals "can" and "will", while other modals, except for "shall", were used sparingly in their written works. The following analysis shows the syntactically accurate and inaccurate modals.

\subsection{Syntactically Accurate Modal Verb Phrases}

Two samples of syntactically accurate modal verb phrases are given below:

1) For example my friend, Ah Ming in Malaysia can stay connected with his sister Ah Ling in Singapore by using Facebook. (F5-1000)

2) Every user has to pay their attention to this, because we do not know who the one are is going to read that and even use that. (F5-772)

Malaysian students like to use the modal "can". Thus, sentence (1) shows the correct usage of the modal verb. In sentence (2) the subject of the sentence "every users" is considered grammatically inaccurate as singular determiner "every" must be followed by the word "user". However, for the purpose of this study, the sentence is deemed syntactically accurate despite the error as appropriate verb form is used to appear with the modal. The examples above indicate students' knowledge and their capability of using the correct modal verbs in their sentences.

\subsection{Syntactically Inaccurate Modal Verb Phrase}

Two examples of syntactically inaccurate modal verb phrase are given below:

3) A future that full of hope could ruined in a momentarily. (F5-766)

4) Majority of the people will on their Facebook account once they online and this had already become as a very common habit for all. (F5-743)

The error found in sentence (3) was with the verb form, where the base form of the verb "ruin" should be used after the modal verb. Similar error was found in several other sentences. In sentence (4) the modal "will" appeared without a verb form ("will" on their Facebook) and also another possible error in verb form ("became" instead of "become"). Several errors that were similar in nature were found in the students' argumentative essays. In summary, inaccurate modal structures could be categorized into:

1) Modal + wrong verb forms: non-infinitives

2) Modal + a non-verb word/lack of verb/non-English word

Due to time constraint and lack of manpower, these categories are not discussed in this study.

\section{Conclusions and Recommendations}

\subsection{Conclusions}

The purpose of this study is to recognize the modals used by Malaysian ESL learner at syntactic level and also relate to how well they can use modal verbs in their writing. The findings of this study were extracted from the argumentative essays with the title "Do You Think Facebook Has More Advantages than Disadvantages?" The essays were piled up in the MCSAW (Malaysian Corpus of Students' Argumentative Writing) Corpus.

From the findings, conclusions become evident and they are related on how Malaysian students use modal verbs in their essay writings. They are:

1) The students realize that modals should come with a verb and that modals are helping or auxiliary verbs.

2) Students showed the ability to utilize modal verbs that are not set in the syllabus (would and shall), thus demonstrating that the learning of modal auxiliary also takes place outside the classrooms.

\subsection{Recommendations}

Below are the recommendations which can be projected in reference to the learning and teaching of modal verbs: 
1) To improve understanding on modals, the teaching of modals should be done in a structured way. From the findings, it can be seen that students do not only learn how to use modals in the classroom but also outside the classroom. However, it was found that most of the modal verbs used by the students were modals of ability.

2) In teaching modals, teachers must be clear of the meanings and how to use them. Any vague meanings of the modals must be clearly explained to ensure better comprehension of the modals.

3) Clear teaching of the five different structures mentioned in the earlier chapter is essential to ensure students' ability to see the different verb forms used in the five different structures. Thus, with better understanding, students can use modals in their writing effectively.

4) The structures introduced to students should be done repeatedly to improve students' comprehensionand recognition of the structures before they fade away from their memories.

Moreover, teachers need to have ample understanding of the usage of the modal auxiliary system so that it can be fully accepted by the students (Thompson, 2002). Only then can all its complexities and ambiguities be acknowledged.

\section{References}

Biber, D., Conrad, S., \& Reppen, R. (1998). Corpus Linguistic: Investigating Language Structure and Use. Cambridge: Cambridge University Press.

Byrd, P. (2004). The difficult-easy matrix: Analyzing grammar from two points of view. Retrieved March 8, 2004, from http://www.gsu.edu/ eslhpb/grammar/difmatrx.htm

Celcie-Murcia M., \& Larsen-Freeman, D. (1983). The Grammar Book: An ESL/EFL Teacher's Course (p. 654). USA: Newbury House.

Coates, J. (1983). The Semantics of the Modal Auxiliaries (p. 269). London: Croom Helm.

De Silva, S. (1981). Forms and Functions in Malaysian English: The Case of Modals. SARE, 3, 11-23

Ferris, D. R. (2002). Treatment of Errors in Second Language Student Writing. Ann Arbor: The University of Michigan.

Hermerén, L. (1978). On Modality in English: A Study of the Semantics of the Modals. Lund: CWK Gleerup.

Hoye, L. (1997). Adverbs and Modality in English. London: Longman.

Hughes, R., \& Heah, C. (1993). Common Errors in English: Grammar Exercises for Malaysians. (2nd. ed.). Shah Alam: FajarBakti.

Krejcie, R. V., \& Morgan, D. W. (1970). Determining Sample Size for Research Activities. Educational Psychological Measurement, 30, 608.

Leech, G., Deuchar, M., \& Hoogenraad, R. (1982). English Grammar for Today: A New Introduction. London: Macmillan Education.

Lyons, J. (1977). Semantics, 2. Cambridge: Cambridge University.

Ministry of Education Malaysia. (2003). Curriculum specifications for English language form 5. Kuala Lumpur: Curriculum Development Centre.

Mindt, D. (1995). An Empirical Grammar of the English Verb: Modal Verbs (p. 183). Berlin: Cornelsen.

Mukundan, J., \& Khojasteh, L. (2011). Modal Auxiliary Verbs in Prescribed Malaysian English Textbooks. English Language Teaching, 4(1), 79-89.

Mukundan, J., Leong, A., \& Nimehchisalem, V. (2012). Distribution of articles in Malaysian secondary school English language textbooks. English Language and Literature Studies, 2(2), 62-70.

Mukundan, J., \& Menon, S. (2008). Nouns and their extended units of meaning: A corpus analysis of nouns used in the Science and English Language textbooks. Jurnal Sastra Inggris, 8(2), 90-111.

Mukundan, J., \& Rezvani Kalajahi, S. A. (2013). Malaysian Corpus of Students'Argumentative Writing $(M C S A W)$. Australia, Australian International Academic Center.

Mukundan, J., \& Roslim, N. (2009). Textbook Representation of Prepositions. English Language Teaching, 2(4), 13-24.

Oakes, M. P. (1998). Statistics for Corpus Linguistics. Edinburgh: Edinburgh University Press.

Palmer, F. R. (1990). Modality and the English Modals. London: Longman. 
Pillay, H., \& North, S. (1997). Tied to the Topic: Integrating Grammar and Skills in KBSM. The English Teacher, 26.

Powell Ronald, R. (1991). Basic research methods for librarians (p. 281, 3rd ed.). London: Ablex Pub. Corp.

Quirk, R., \& Stein, G. (1990). English in Use. London: Longman.

Reppen, R., et al. (2002). Using Corpora to Explore Linguistic Variation. Amsterdam: John Benjamins.

Rosli Talif, \& Malachi, E. (1989). Error Analysis of Form Four English Compositions. The English Teacher, 28.

Samad, A. A., Hassan. F., Mukundan. J., Kamarudin. G., Abd. Rahman S. Z. S., Rashid. J., \& Vethamani. M. E. (2002). The English of Malaysian School Students (EMAS) Corpus. Serdang: UPM.

Stockwell, R. P. (1977). Foundations of Syntactic Theory (p. 216). Englewood Cliffs, New Jersey: Prentice Hall.

Stubbs, M. (1983). Discourse analysis: The sociolinguistic analysis of natural language. Oxford: Basil Blackwell.

Thompson, M. (2002). Modals in English Language Teaching. Retrieved April 28, 2013, from http://www.telusplanet.net/linguisticsissues/modalsinteaching.html

Van Valin, J. R. (2001). An introduction to syntax (p. 239). Cambridge: Cambridge University Press.

Vethamani, M. E. (2001). What English do we teach? The English Teacher, 30.

Vethamani, M. E. (2007). The Ebb and Flow of English Language Education in Malaysia. In Vethamani, M. E., \& Rajandaran Perumal (Eds.), Teaching English in Malaysia. Petaling Jaya: SasbadiSdn. Bhd.

Wong, I. (1983). Simplification features in the structure of colloquial Malaysian English. In Noss, R. (Ed.), Varieties of English in South East Asia (pp. 125-149). Singapore: Singapore University Press (for SEAMEO).

\section{Copyrights}

Copyright for this article is retained by the author(s), with first publication rights granted to the journal.

This is an open-access article distributed under the terms and conditions of the Creative Commons Attribution license (http://creativecommons.org/licenses/by/3.0/). 